\title{
Minor Groove
}

National Cancer Institute

\section{Source}

National Cancer Institute. Minor Groove. NCI Thesaurus. Code C13742.

The smaller of the two types of spiral grooves found on a right-handed DNA double helix; located between the sug ar phosphate backbones of two DNA strands. 